\title{
A scientometric review of multimedia in teaching and learning of physics
}

\author{
Pascasie Nyirahabimana ${ }^{1}$, Evariste Minani ${ }^{1}$, Mathias Nduwingoma ${ }^{1}$ \\ and Imelda Kemeza² \\ ${ }^{1}$ University of Rwanda-College of Education, African Center of Excellence for \\ Innovative Teaching and Learning Mathematics and Science, Kayonza, Rwanda \\ ${ }^{2}$ Mbarara University of Science and Technology, Uganda
}

A subject of physics includes various complex and sophisticated concepts that pose a challenge for both instructors to teach and students to grasp the clarity in the subject. Many researchers have discussed this challenge toward adopting an appropriate approach to teach physics in the institution. Therefore, the study reviews the research articles towards multimedia in improving the knowledge delivery system of physics published in various standard databases/indexes. The study conducts a literature review based on five-stage methodology comprising of: (1) research article collection from the databases, (2) research article inclusion/exclusion norms, (3) reviewing the processed research articles, (4) analyzing the research articles to extract the information, and (5) inferring the extracted information to derive at the future research direction. The paper contributes to reviewing thirty-three research articles specific to the usage of multimedia towards improving the methodologies involved in teaching and learning physics. The core idea of this study is to extract the research gaps on the usage of multimedia in the current knowledge delivery system of the physics domain to provide future research directions. Further, a bibliometric analysis comprises co-occurrence of keywords, citation, and co-citation using VOSviewer software. It is followed by content analysis to analyze the research method and multimedia tool used. The study outcome shows that most of the existing work found is Quasi-experimental design-based or qualitative design-based. The study outcome also highlights various themes of accepted papers and research gaps on the usage of multimedia in the knowledge delivery system of the physics domain.

\section{ARTICLE DETAILS}

LUMAT General Issue Vol 10 No 1 (2022), 89-106

Received 8 July 2021 Accepted 7 February 2022 Published 8 March 2022

Pages: 18

References: 27

Correspondence: pnyirahabimana@gmail.com

https://doi.org/10.31129/ LUMAT.10.1.1634

Keywords: Multimedia, literature review, bibliometric analysis, physics

\section{Introduction}

Education has been identified as one of the public sectors that are mainly influenced by technological developments. With the introduction of technology in education, changing the role of education explicitly in physics is inevitable. The role of physics in science and technology has enhanced research to present the subject in new ways in physics courses (Jian-hua and Hong, 2012). E.g., Quantum physics (modern and mechanics) is a challenging subject students encounter in mechanics is a challenging subject student to encounter in their physics curriculum (Wuttiprom et al., 2009). 
One of the critical challenges in quantum physics is finding a way to introduce the concepts as quantum theory is technically and theoretically subtle. Most of the physics concepts are derived via theories and complex mathematical problems. Therefore, it is difficult for students to understand the concepts and mathematical formulas in a short time interval. The advantage of multimedia applications in the classroom is a dynamic simulation, i.e., the students get interested in the subject through visual experiments and animations (Kohnle et al., 2013). Multimedia aided technology helps students grasp and understand physics concepts and laws swiftly. It solves vital and complex points for teaching, dealing with theories, processes, and phenomena that are difficult to understand via the conventional chalkboard approach (Zainuddin et al., 2019). The application of multimedia-aided technology in the physics curriculum not only saves time but makes theory content more understandable through visuals and intuitive via a combination of video and audio means (Gunawan et al., 2019). The teaching efficiency and quality are greatly improved with multimedia-aided technologies, and it also helps to accommodate and promote the students with their talent (Bungum et al., 2018). The effective use of multimedia aided technology in teaching physics can change the process of learning with the help of simulations, visuals, animations, and graphs, which enhances teaching content and helps the students to get involved in discussions and multimedia activities, mastering the physics concepts and knowledge (Mason and Singh, 2010). Multimedia applications can make the teaching content intuitive inspiring enthusiasm among students improving their learning efficiency.

There have been various contributions to signifying the importance of the inclusion of multimedia towards knowledge delivery systems exclusively for physics. However, there is no reported work to visualize the quantified research trends towards this form of adoption to understand the methodologies that have evolved to date. Hence, there is a need to investigate this fact more precisely to assist the upcoming researchers in concluding the best form of teaching and learning methodologies towards physics. Therefore, the present study contributes towards reviewing the existing standard articles on the themes of inclusion of multimedia as a part of methodologies in teaching and learning physics and investigates the trends of publications over the period (2006-2021) to exhibit significant future research directions in the physics domain. To accomplish the goal of the present study, the following research questions are considered: 
RQ1: What is the trend of publication on the use of multimedia in teaching and learning physics over the years?

RQ2: What are the maximum cited studies on the use of multimedia in teaching and learning physics?

RQ3: What is the citation and co-citation pattern for all possible cited works on the use of multimedia in teaching and learning physics?

RQ4: What are the tools/methods adopted towards research on multimedia in teaching and learning physics?

RQ5: What multimedia tools are used in the existing studies on multimedia in teaching and learning physics?

Further, the paper's organization is as follows: the following segment talks about the outline of the past studies on multimedia in teaching and learning of physics, trailed by a discussion of the methodology adopted to carry out the scientometric analysis. Consequently, data about bibliometric analysis (BA) on existing multimedia in teaching and learning physics studies and content analysis (CA) of the selected studies from the database are covered. Further, the findings, research gaps, and future research directions are provided. The last section provides the conclusion of the study.

\section{Literature review}

The conventional teaching and learning of physics have been dominated by mathematical problem-solving rather than critical thinking, discussion of ideas, and qualitative understanding of the subject (Ayene et al., 2011). Quantum physics is a part of the physics curriculum, including both modern physics and quantum mechanics. Various studies have identified that learning physics is challenging for students (Henriksen et al., 2014; Chhabra and Das, 2016; Lai and Bower, 2019). These studies exhibit that students often have difficulties in understanding the nondeterministic nature of quantum phenomena. Technology has emerged as a powerful tool to help students understand physics more efficiently and in detail. With the emergence of technologies available for use in education, it is important to integrate technology into the teaching and learning process to improve student's critical thinking, concept-building, and motivation (Kohnle et al., 2012). Mayer (2011) states that animations in classrooms improve the conceptual understanding of the subject. 
Multimedia provides educators with the opportunity to control every phase of instruction by planning and selecting the visualization that a learner receives (Rusanganwa, 2013). Pun (2014) investigates the integration of technology (ICT) in education. The study used multimedia learning to explore the classroom environment in understanding physics. The results exhibit that multimedia learning significantly impacts recalling the physics concepts taught in the classroom. Combining multimedia-aided teaching with the teachers' subjective knowledge helps in physics teaching and enhances the classroom's teaching effect. Chen et al. (2010) state that computers act as a powerful tool to facilitate the science curriculum and help students and teachers to understand the subject. Specifically, multimedia has vastly improved students' understanding of the subject (Radlovic-Cubrilo et al., 2014). Newman and Gough (2019) performed an investigation to evaluate multimedia applications' impact on teaching physics in the classroom. The study examined the influence of multimedia applications on the quantum theory and retention of concepts by students. The findings indicate that multimedia application increased students' quantum knowledge and the recall of subjects compared to the increased teaching method. The results suggest that multimedia applications enhance understanding of physics concepts and enhance teaching physics efficiency in the classroom.

In this review, the articles published on multimedia in the teaching and learning physics domain were searched and collected first. Further, the articles collected from various databases are shortlisted for review. Then the bibliometric and content analyses are carried out on the shortlisted articles using VOS viewer and MS-Excel tool to find out the publication trends, type of studies, the journal's scope, and research gaps for future research directions. The detailed review methodology used for conducting a literature review is explained in section 3 .

\section{Methodology}

Methodology refers to the research strategies that outline how the research will undertake the research problem. The present study considers literature review methodology, which is most appropriate when the research aims to determine the recent trend of studies and identifies the conceptual works for future research (Hopia et al., 2016). The study adopted a "five-stage method" proposed by Dohale et al. (2020) to search, locate, select, review, and analyze the selected articles on the use of multimedia in teaching and learning physics. 


\subsection{Stage I: Research article collection}

In order to perform BA, the first stage is to decide and collect the data sources those best suit the coverage of the research domain. For an assortment of articles, keywords (KW) such as multimedia in teaching and learning and multimedia in teaching and physics are used. The snowball method is used to identify the articles, including tracking down the extra KW through the KW utilized at first looking through articles. It is found that the number of bibliographic databases is high (e.g., PubMed, Springer Link, EBSCO, etc.), but not all of them provide information that allows the efficient performance of the BA (Moral-Muñoz et al., 2020) due to certain constraints. Thus, three major academic databases- Scopus, Thomson Reuters, and Taylor \& Francisare used to identify the journal articles.

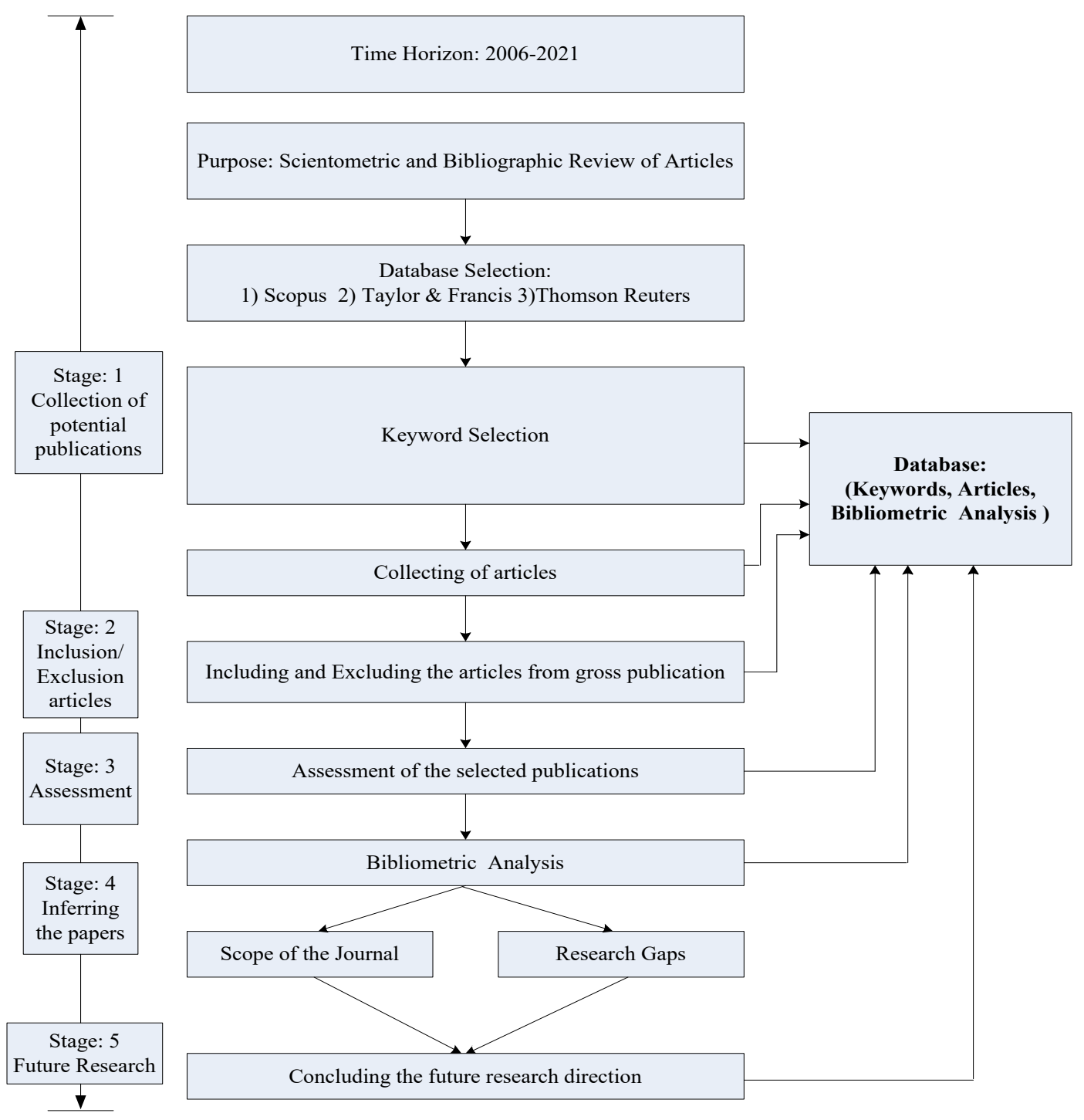

Figure 1. Literature Review Methodology 
To gather relevant articles specific to the study's purpose, KW is joined utilizing AND/OR operations in the advanced search option of the database. An aggregate of 89 articles distributed in various journals has been distinguished (refer to Table 1).

\subsection{Stage II: Research article inclusion/exclusion norms}

The current study reviewed and analyzed the articles on multimedia in the teaching and learning of physics in various journals. The study used an abstract screening technique to determine the most relevant articles on multimedia in the teaching and learning of physics. Out of the 89 articles, 33 articles aligned with multimedia teaching and physics learning are used for literature review and analysis. Table 1 shows the distribution of research articles found in the selected databases concerning search criteria and keywords and search strings used to find the articles.

Table 1. Articles Identified from the selected databases

\begin{tabular}{llccc}
\hline Keyword String & Search Criteria & Scopus & Taylor \& Francis & $\begin{array}{c}\text { Thomson } \\
\text { Reuters }\end{array}$ \\
\hline $\begin{array}{l}\text { Multimedia in Teaching } \\
\text { and Learning }\end{array}$ & $\begin{array}{l}\text { Title/Abstract/ } \\
\text { Keywords }\end{array}$ & 920 & 765 & 539 \\
\hline $\begin{array}{l}\text { "Multimedia in Teaching } \\
\text { and Learning in Physics" }\end{array}$ & $\begin{array}{l}\text { Title/Abstract/ } \\
\text { Keywords }\end{array}$ & 40 & 32 & 17 \\
\hline \multicolumn{2}{l}{ Total articles found from all the databases } & & 89 & \\
\hline Selected Articles & & & 33 & \\
\hline
\end{tabular}

\subsection{Stage III: Literature review}

The selected articles have been scanned and reviewed to determine the type of tool/method used for conducting a study and the type of multimedia tool used in the study, highlighting the significant contribution from each study.

\subsection{Stage IV: Analysis of the research articles}

The selected 33 articles have undergone a bibliometric and content analysis. A bibliometric analysis is carried out using the VOSviewer, while the MS Excel tool is utilized for carrying out the content analysis. A bibliometric analysis consists of the trends of publication, year-wise and country-wise. Furthermore, keyword analysis is also carried out in a bibliometric analysis, which determines the frequency of co- 
occurrence. In addition, content analysis is carried out to identify the tools/methods used for conducting research and the multimedia tools adopted in the study. Further, the results of both analyses are discussed in detail in section 5 to determine the research gaps.

\subsection{Stage V: Future research work}

The exploration gaps identified from the analysis are provided in the discussion section. Based on the gaps, further works to be carried out are also determined. The research ramifications of the study, both in theory and practice, are likewise provided in the discussion section.

\section{Bibliometric and content analysis}

\subsection{Bibliometric analysis:}

The bibliometric analysis framework followed in this study is adopted from Amoozegar et al. (2018). A total of 33 articles have been shortlisted using the search setting explained in Table 4. Out of the 33 articles shortlisted, only one article is found on multimedia in teaching and learning physics.

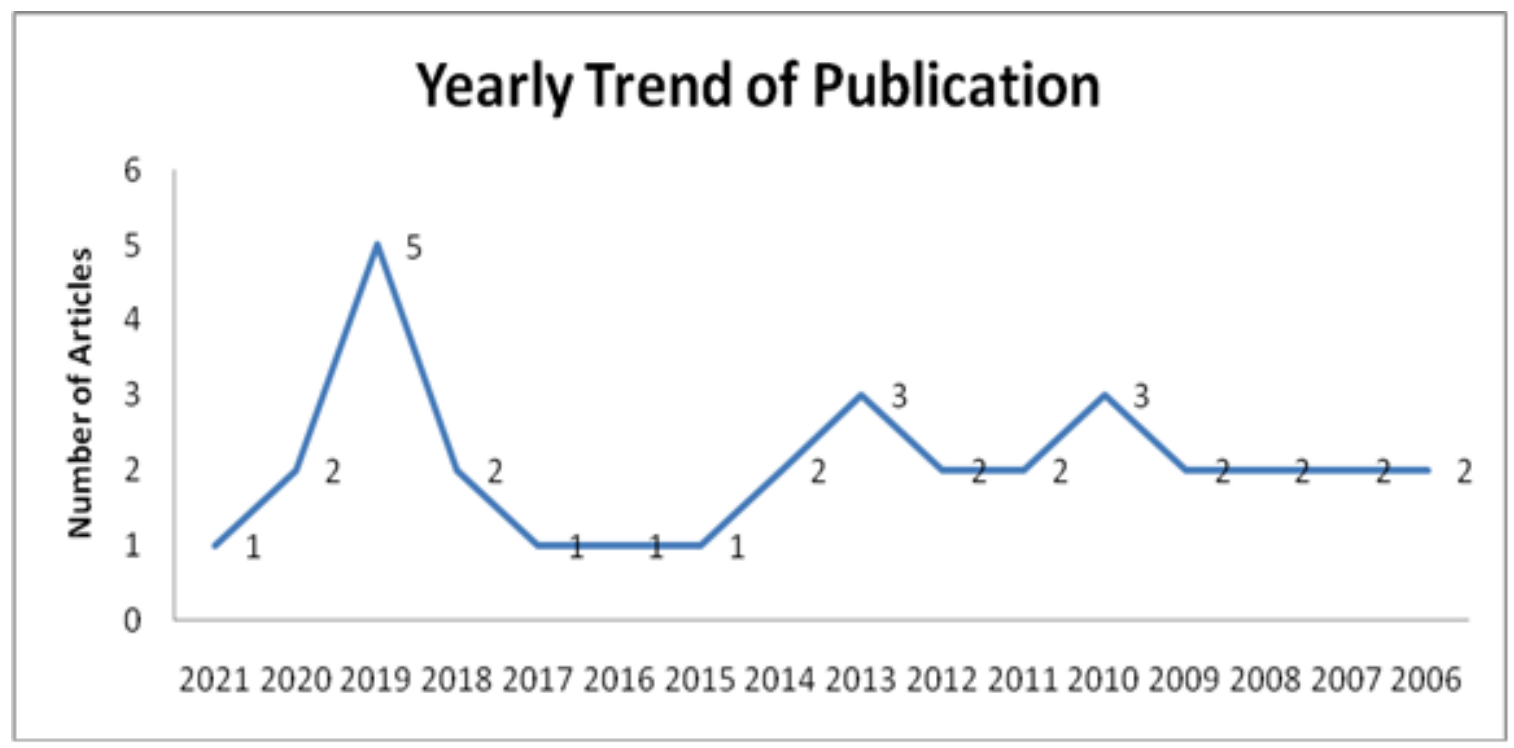

Figure 2. Year-wise distribution of articles related to the use of multimedia in teaching and learning physics 
Further, a bibliometric analysis is performed to analyze the contribution by countries. Table 2 shows the country-wise distribution of articles. Germany dominates the list of publications with seven articles out of all the articles from multimedia in teaching and learning physics. Indonesia, Italy, Poland, the United Kingdom, and the United States list countries with five articles, followed by Austria with three articles. The rest of the contribution on multimedia articles in teaching and learning physics can be found very low.

Table 2. Country-wise distribution of articles

\begin{tabular}{|c|c|c|c|c|}
\hline Country & Documents & $\%$ of documents & Citations & $\begin{array}{c}\text { Average citations per } \\
\text { document }\end{array}$ \\
\hline Austria & 3 & 4.839 & 16 & 5.3 \\
\hline Belgium & 2 & 3.226 & 0 & 0 \\
\hline Cuba & 1 & 1.613 & 0 & 0 \\
\hline Finland & 1 & 1.613 & 1 & 1 \\
\hline France & 1 & 1.613 & 1 & 1 \\
\hline Germany & 7 & 11.290 & 41 & 5.9 \\
\hline Greece & 4 & 6.452 & 14 & 3.5 \\
\hline Hungary & 2 & 3.226 & 1 & 0.5 \\
\hline Indonesia & 5 & 8.065 & 9 & 1.8 \\
\hline Italy & 5 & 8.065 & 18 & 3.6 \\
\hline Kenya & 1 & 1.613 & 0 & 0 \\
\hline Mexico & 1 & 1.613 & 13 & 13 \\
\hline Morocco & 1 & 1.613 & 5 & 5 \\
\hline Netherlands & 2 & 3.226 & 1 & 0.5 \\
\hline Norway & 1 & 1.613 & 1 & 1 \\
\hline Poland & 5 & 8.065 & 18 & 3.6 \\
\hline Portugal & 2 & 3.226 & 16 & 8 \\
\hline Rwanda & 2 & 3.226 & 23 & 11.5 \\
\hline Spain & 1 & 1.613 & 1 & 1 \\
\hline Sweden & 2 & 3.226 & 22 & 11 \\
\hline Switzerland & 1 & 1.613 & 1 & 1 \\
\hline Taiwan & 2 & 3.226 & 63 & 31.5 \\
\hline United Kingdom & 5 & 8.065 & 55 & 11 \\
\hline United States & 5 & 8.065 & 32 & 6.4 \\
\hline
\end{tabular}




\subsection{Keyword analysis}

The three widely used approaches in a bibliometric analysis for visualizing bibliometric networks are distance-based, graph-based, and timeline-based networks. The distance-based bibliometric network represents the association's strength between the two nodes (Girwidz et al., 2019). VOSviewer software is used to draw a distance-based bibliometric network to illustrate publication characteristics through bibliometric network analysis.

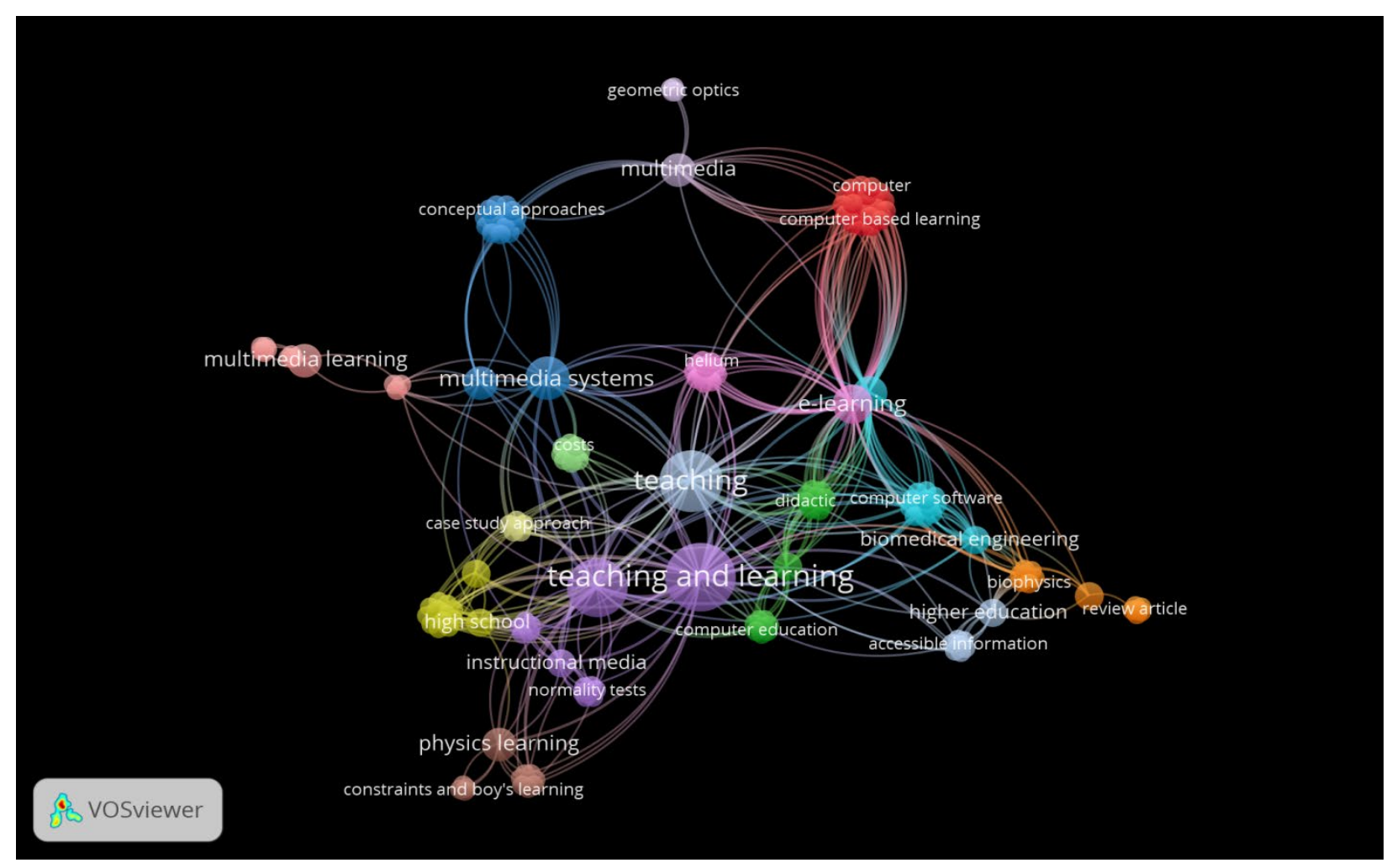

Figure 3. Bibliometric networks: Co-occurrence of keywords

The articles are analyzed concerning keywords used in all the selected articles using VOS viewer. Figure 3 shows the network of co-occurrence of keywords used in articles. The different colored clusters of keywords are formed in the network, as shown in Figure 3. The study had utilized VOSviewer software to draw a distancebased bibliometric network to elucidate articles' characteristics through bibliometric network analysis. The publications are evaluated concerning the keywords used in all the selected articles using the software. The bibliometric networks show the cooccurrence of keywords, which specifies keyword occurrence frequency with the other keywords. Figure 3 shows that teaching and learning are the primary keywords frequently used in the bibliometric network. 
Further, in the co-occurrence analysis, teaching and learning (purple cluster) are primarily used with teaching, physics learning, students, and multimedia systems. On the other hand, the keyword multimedia (shown in a blue cluster) has been used frequently with conceptual approaches, computer-based learning, and e-learning. Based on the keyword clusters formed, the publications are categorized into three major clusters of keywords which are determined as a subject area in this study: (1) teaching and learning, (2) multimedia, and (3) students. The teaching and learning keyword is used widely, with almost 25 occurrences with a link strength of 347 . Similarly, multimedia keywords occurred 22 times with a link strength of 243. The student keyword has been used 14 times with a link strength of 187.

\subsection{Citation analysis (CA)}

CA is a subgroup of the bibliometric network providing evidence about the degree of an article's impact on a particular area (Aksnes et al., 2019). It determines the connection of publications and aids in comprehending the importance of referring publications with the referred articles. Hence, CA offers understanding into significant articles in a particular area and gives a framework of citations an article has received. CA is carried out on 33 research works on multimedia in teaching and learning physics.

Table 3 lists the top-cited articles on the theme of multimedia in teaching and learning physics. The table demonstrates that aggregate citations of 203 have been acknowledged with a mean citation of 12.68 .

Table 3. Highly cited articles

\begin{tabular}{|c|c|c|c|c|}
\hline SI. No & Document & Year & Citations & $\begin{array}{l}\text { Average } \\
\text { Citations }\end{array}$ \\
\hline 1 & $\begin{array}{l}\text { Effectiveness of PhET Simulations and YouTube Videos } \\
\text { to Improve the Learning of Optics in Rwandan } \\
\text { Secondary Schools }\end{array}$ & 2020 & 2 & 0.99 \\
\hline 2 & $\begin{array}{l}\text { Physics teaching and learning with multimedia } \\
\text { applications: a review of teacher-oriented literature in } \\
34 \text { local language journals from } 2006 \text { to } 2015\end{array}$ & 2019 & 1 & 0.49 \\
\hline 3 & $\begin{array}{l}\text { The importance of multimedia learning modules } \\
\text { (MLMS) based on local wisdom as an instructional } \\
\text { media of 21st-century physics learning }\end{array}$ & 2018 & 1 & 0.49 \\
\hline 4 & $\begin{array}{l}\text { Undergraduate student's conceptual interpretation } \\
\text { and perceptions of haptic-enabled learning } \\
\text { experiences }\end{array}$ & 2017 & 13 & 6.40 \\
\hline
\end{tabular}




\begin{tabular}{|c|c|c|c|c|}
\hline 5 & $\begin{array}{l}\text { Interactive simulations for teaching and learning } \\
\text { differential equations }\end{array}$ & 2016 & 5 & 2.46 \\
\hline 6 & $\begin{array}{l}\text { A novel educational platform, based on the Raspberry- } \\
\mathrm{Pi} \text { : Optimised to assist the teaching and learning of } \\
\text { younger students }\end{array}$ & 2014 & 5 & 2.46 \\
\hline 7 & $\begin{array}{l}\text { Report and recommendations on multimedia materials } \\
\text { for teaching and learning electricity and magnetism }\end{array}$ & 2013 & 16 & 7.88 \\
\hline 8 & $\begin{array}{l}\text { Multimedia as a means to enhance teaching technical } \\
\text { vocabulary to physics undergraduates in Rwanda }\end{array}$ & 2013 & 21 & 10.34 \\
\hline 9 & $\begin{array}{l}\text { The impact of technology-enabled active learning } \\
\text { (TEAL) implementation on student learning and } \\
\text { teachers' teaching in a high school context }\end{array}$ & 2012 & 40 & 19.70 \\
\hline 10 & $\begin{array}{l}\text { Integration of knowledge in engineering/science via } \\
\text { nanotechnology programs }\end{array}$ & 2011 & 3 & 1.48 \\
\hline 11 & $\begin{array}{l}\text { High-Tech Kit - The set of advanced activities from the } \\
\text { MOSEM project }\end{array}$ & 2010 & 1 & 0.49 \\
\hline 12 & Research on using robots in education & 2009 & 23 & 11.33 \\
\hline 13 & $\begin{array}{l}\text { Constructivist learning and teaching of optics concepts } \\
\text { using ICT tools in Greek primary school: A pilot study }\end{array}$ & 2009 & 9 & 4.43 \\
\hline 14 & $\begin{array}{l}\text { Developing media-rich virtual learning material for } \\
\text { biomedical engineering education }\end{array}$ & 2008 & 1 & 0.49 \\
\hline 15 & Multimedia representation of experiments in physics & 2007 & 24 & 11.82 \\
\hline 16 & $\begin{array}{l}\text { The impact of authentic learning on students' } \\
\text { engagement with physics }\end{array}$ & 2006 & 38 & 18.72 \\
\hline
\end{tabular}

\subsection{Co-citation network analysis}

It is characterized as the frequency with which two researchers' articles have been referred together by different articles (García-Lillo et al., 2019). It indicates the theoretical connection between the cited and citing documents. The cited articles' references are scanned in the co-citation analysis, and the outcome exhibits a comprehensive understanding of scholarly impact in the literature (Krippendorff, 2018). Figures 4 and 5 show the co-citation network created for cited authors and sources. The co-citation network for the author helps in determining the scholarly framework. The co-citation network shows Prof. Mayer, Prof. Mishra, Prof. Driver, Prof. Galili, Prof. Hestenes, Prof. Jones, Prof. Jonassen, Prof. Koehler, Prof. Tondeur, and Prof. Van Braak are the most prominent nodes in the co-citation network for authors.

On the other hand, the co-citation network for sources exhibits American Journal of Physics, International Journal of Science Education, European Journal of Physics, British Educational Research Journal, and African Journal of Research in 
Mathematics, Science and Technology Education, and Journal of Research in Science Teaching are the eminent nodes in the source's co-citation network.

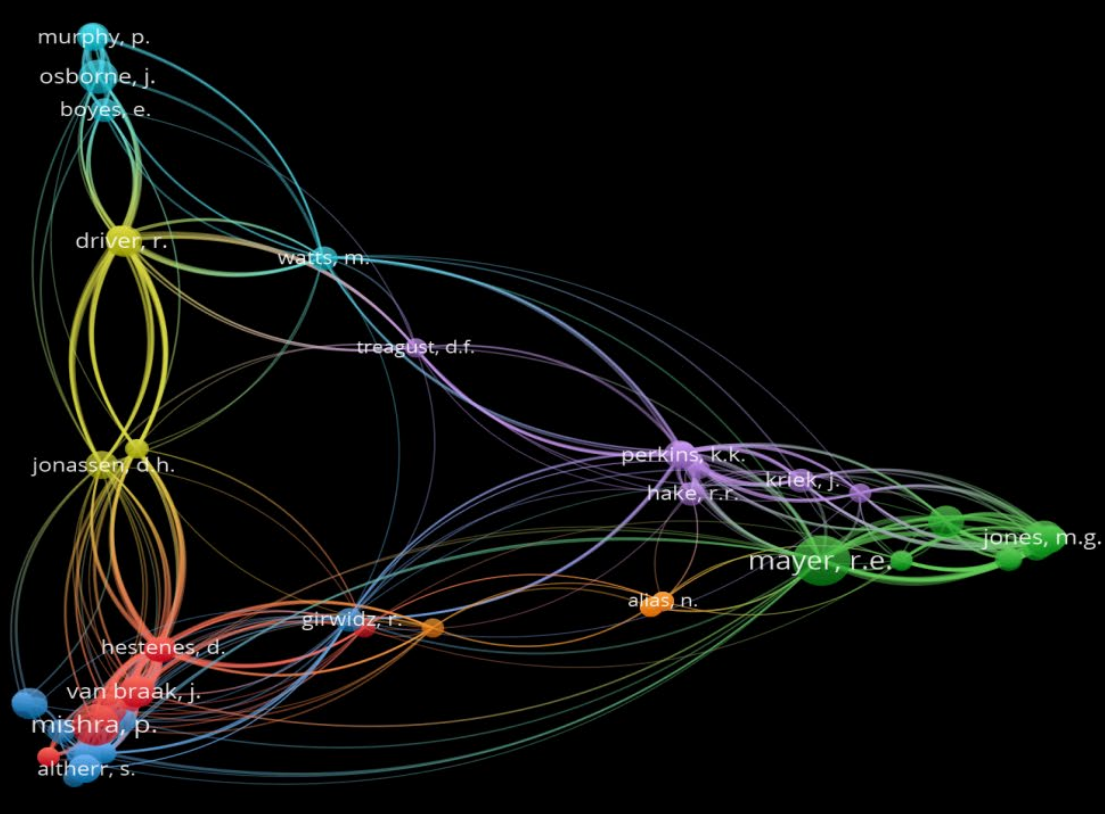

Figure 4. Co-citation network analysis for authors

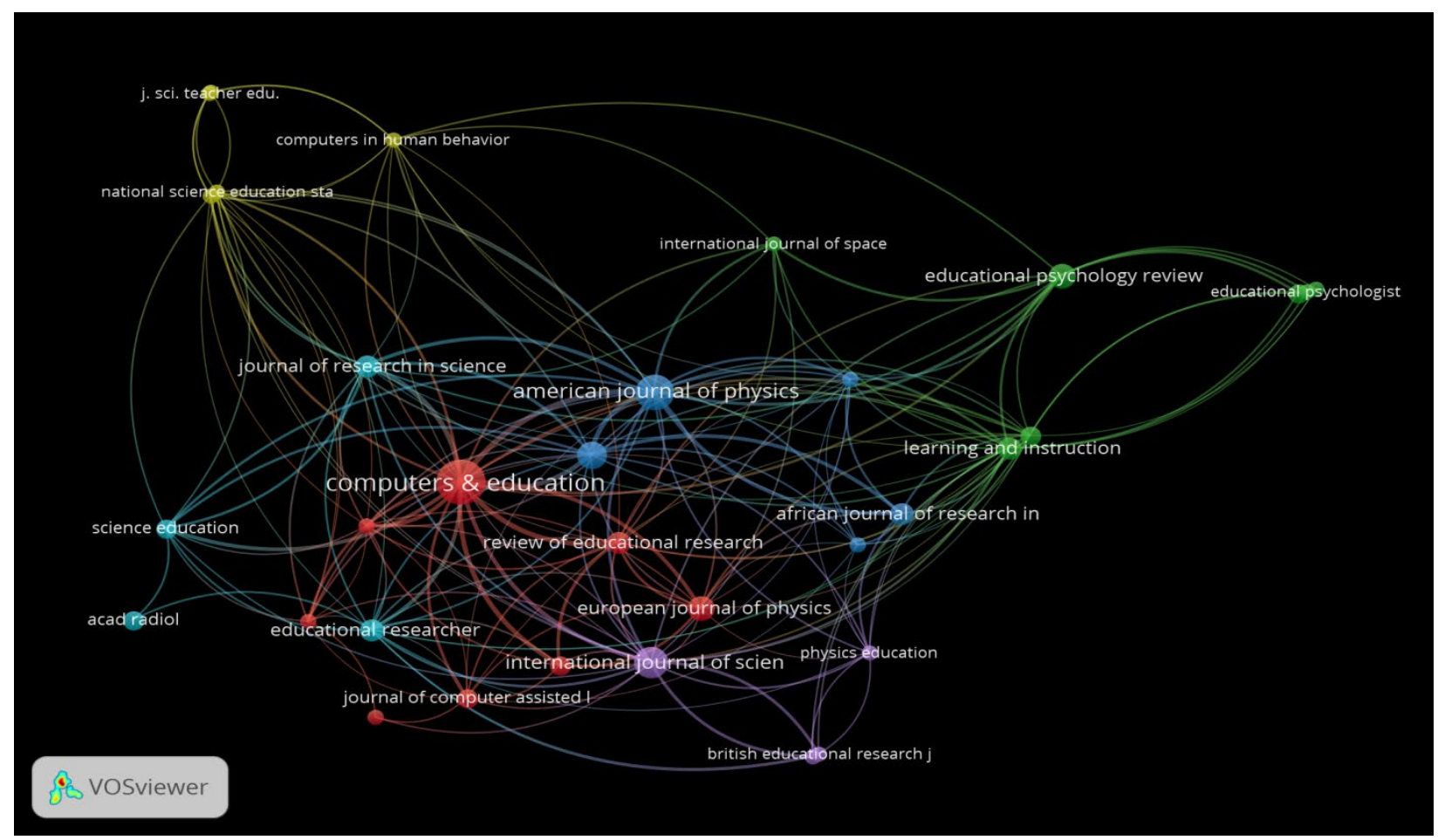

Figure 5. Co-citation network analysis for sources 


\subsection{Content analysis}

Content analysis is the systematic study of document artifacts: texts, images, or other symbolic matter (Vaismoradi et al., 2016). It is a methodology that aids in analyzing a huge set of data in a systematic order. Content analysis was performed on the selected 33 articles on multimedia in teaching and learning in physics to determine the selected domain's research studies trend. The study had created a database of the selected articles in MS-Excel to assist the sample's classification based on 1) tools/methodology adopted and 2) the type of multimedia tools used.

Tools /methods adopted in the research

Figure 6 exhibits the tools/methods adopted in the selected articles on multimedia in teaching and learning physics. The outcome demonstrates that Quasi-experimental design is widely used in research studies, followed by survey and qualitative design.

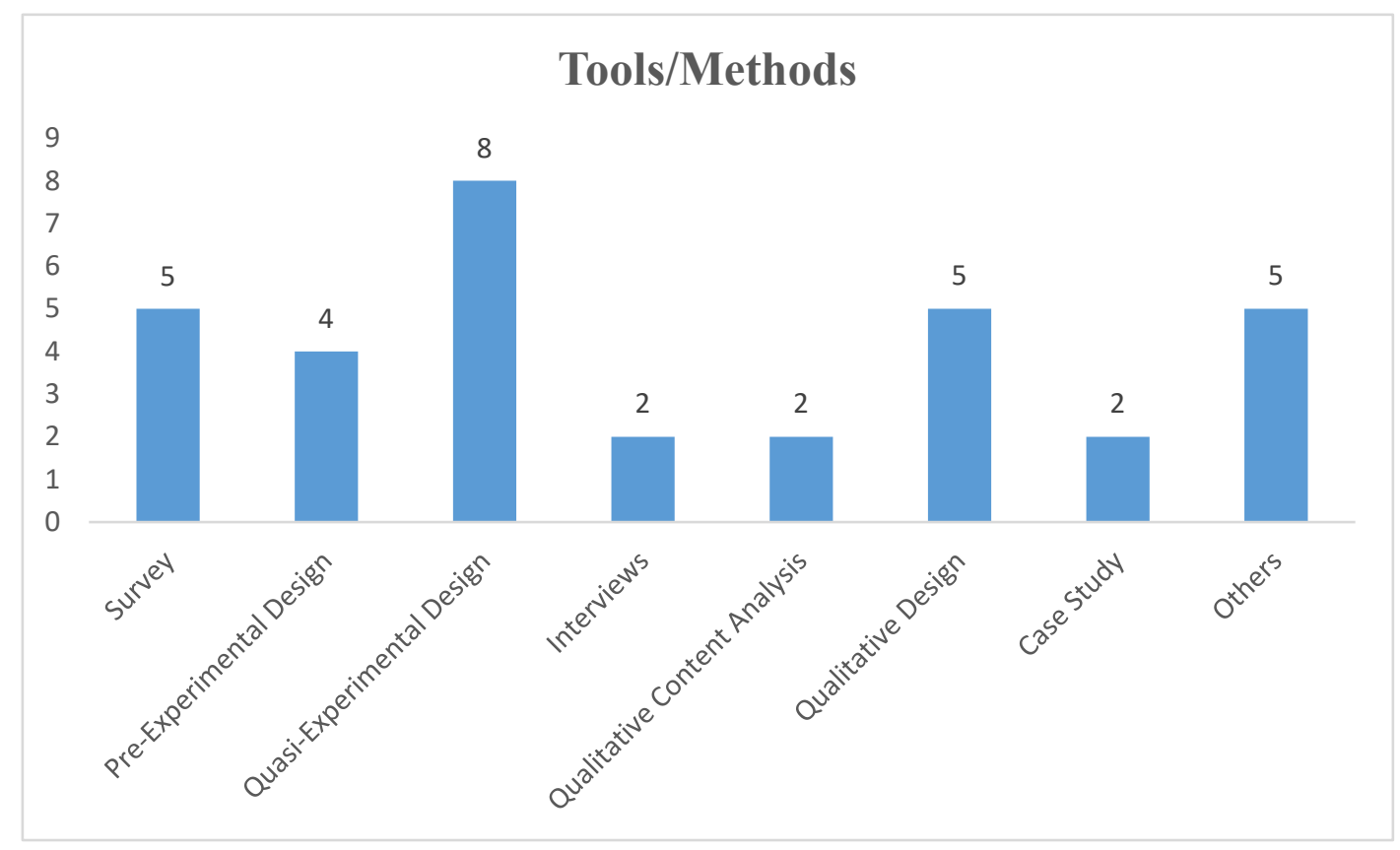

Figure 6. Classification based on tools/methods used

Type of multimedia used in the study

This section identifies the types of multimedia tools used in the research articles. Table 4 exhibits the multimedia tools used in the teaching and learning of physics. Some of the studies have not specified the types of multimedia tools represented by others. 
Table 4. Multimedia tools

\begin{tabular}{lc}
\hline Multimedia Tools & Articles \\
\hline Mind Map & 3 \\
Instructional Media (Lectora Inspire) & 1 \\
PhET simulation \&Youtube videos & 1 \\
Simulations and Visualization & 7 \\
Audio and video & 3 \\
PhET, Quvis, Quantum Lab & 1 \\
Computer-mediated multimedia & 1 \\
TEAL & 1 \\
M.A.T.H.I.M.A \& Reflection and diffusion & 1 \\
Animations & 4 \\
Video Lectures & 3 \\
Visualization & 3 \\
Computer Assisted learning & 1 \\
Others & 3 \\
\hline
\end{tabular}

\section{Discussion}

The study gives a scientometric review of the articles on multimedia in teaching and learning of the physics field distributed over the last fifteen years (2006-2021). An aggregate of 33 articles is investigated and sorted. The clusters are created using a KW network structure, and the articles are sorted into those cluster groups. The outcomes from the scientometric analysis can provide insights to researchers willing to publish articles on multimedia in teaching and learning physics and comprehend the research type, themes of papers, and the research gaps identified.

The content analysis statistics exhibit that Quasi-experimental design is widely used in research studies (24\%) followed by survey (15\%), qualitative design (15\%), and pre-experimental design (12\%). Simulations and visualizations have been widely used (7 studies), Animations ( 4 studies), audio, video, and mind map tools (3 studies each).

From the analyses presented in the above sections, a few insights and gaps have been acknowledged to provide insight into future research directions.

Based on the geographical contiguity, Germany has the most substantial number of distributions in the multimedia in teaching and learning of physics domain. European countries account for the greatest number of articles. Asia constitutes seven articles. Latin countries constitute slightly above $15 \%$ of these articles, with five articles, and African nations constitute four. Interestingly, the list has no publication from mainland China and India. Barring the case of China and India, the overall trend 
of publications from various parts of the world indicates broad interest in the topic from across the globe.

The authors' profile from the co-citation network bears testimony that most authors are from Germany, reflecting popularity and collaboration in most cited works in this stream by authors mainly from Germany. The co-citation network analysis of the journals indicates that co-citations are among top-rated journals such as American Journal of Physics, International Journal of Science Education, European Journal of Physics, British Educational Research Journal, and African Journal of Research in Mathematics, Science and Technology Education, and Journal of Research in Science Teaching. Also, reputed journals and authors are interested in publishing on this topic point out its potential for the future.

The KW co-occurrence analysis shows that teaching and learning and students are the KW recurrently used in the network. However, a low proportion of KW cooccurrence between the KW is associated with teaching and learning and students. Also, 33 articles have received 666 citations from the citation network, with a mean of 12.68, comparatively less in number. However, as shown in Figure 2, the number of publications in this stream has risen over the years. Therefore, all these above points exhibit the exciting potential of this research stream and rich avenues to be reaped in the future.

Rationally linking keywords from different KW clusters can also improve the current research state in multimedia in teaching and learning physics. Therefore, further studies can club KW from various cluster groups to make the research area more comprehensive and inclusive in multimedia teaching and learning of physics.

The scientometric can provide key insights to the academicians and professionals working in multimedia in teaching and learning of physics field. Academicians keen to publish in the respective domain can allude to the gaps provided in this study to understand different themes and applications of multimedia in teaching and learning in varied fields. Further, researchers can recognize the acknowledged gaps and direction for further research on unaddressed concerns. The scientometric study assists professionals to comprehend distinctive investigative tools/methods to tackle the issues of multimedia in teaching and learning of physics and further reflect on new strategies/practices for further research works.

Further, educational management and lecturers may benefit from taking time to understand the organizational upside of investing in multimedia in teaching and 
learning of physics for their students since the long-term return of creativity and innovation should compound once the practice has been established.

\section{Conclusion}

This work did an up-to-date systematic review of multimedia in teaching and learning physics literature. A total of 33 selected articles were analyzed and categorized. The clusters of frequently used keywords were created as subject areas, and the articles were categorized into those keyword clusters using a bibliometric analysis of keywords. The content analysis statistics exhibit that most research articles are Quasiexperimental designs followed by survey and qualitative design. The study also exhibits that those simulations and visualizations are the most widely used multimedia tools in the research articles. The study's findings highlight the high potential of research in multimedia in teaching and learning physics as top journals and authors are equally interested in this area. As the number of publications rises in this area, the interested researchers will likely gain by integrating multimedia and teaching and learning research findings. Collaboration with authors from different geographical locations is likely to bring needed new paradigms and perspectives in this area of research.

\section{References}

Aksnes, D. W., Langfeldt, L., \& Wouters, P. (2019). Citations, citation indicators, and Research Quality: An overview of basic concepts and theories. SAGE Open, 9(1), 215824401982957. https://doi.org/10.1177/2158244019829575

Amoozegar, A., Khodabandelou, R., \& Ale Ebrahim, N. (2018). Major trends in distance education research: A combination of bibliometric and thematic analyze. International Journal of Information Research and Review, 5(2), 5352-5359.

Ayene, M., Kriek, J., \& Damtie, B. (2011). Wave-particle duality and uncertainty principle: Phenomenographic categories of description of tertiary physics students' depictions. Physical Review Special Topics - Physics Education Research, 7(2). https://doi.org/10.1103/physrevstper.7.020113

Bungum, B., Bøe, M. V., \& Henriksen, E. K. (2018). Quantum talk: How small-group discussions may enhance students' understanding in Quantum Physics. Science Education, 102(4), 856877. https://doi.org/10.1002/sce.21447

Chen, Z., Stelzer, T., \& Gladding, G. (2010). Using multimedia modules to better prepare students for introductory physics lecture. Physical Review Special Topics - Physics Education Research, 6(1). https://doi.org/10.1103/physrevstper.6.010108

Chhabra, M., \& Das, R. (2016). Quantum mechanical wavefunction: Visualization at undergraduate level. European Journal of Physics, 38(1), 015404. https://doi.org/10.1088/0143-0807/38/1/015404 
Dohale, V., Gunasekaran, A., Akarte, M. M., \& Verma, P. (2020). Twenty-five years' contribution of "Benchmarking: An international journal" to manufacturing strategy: A scientometric review. Benchmarking: An International Journal, 27(10), 2887-2908. https://doi.org/10.1108/bij06-2020-0316

García-Lillo, F., Claver-Cortés, E., Marco-Lajara, B., \& Úbeda-García, M. (2019). Identifying the 'knowledge base' or 'intellectual structure' of research on International Business, 2000-2015: A Citation/co-citation analysis of jibs. International Business Review, 28(4), 713-726. https://doi.org/10.1016/j.ibusrev.2019.02.001

Girwidz, R., Thoms, L.-J., Pol, H., López, V., Michelini, M., Stefanel, A., Greczyło, T., Müller, A., Gregorcic, B., \& Hömöstrei, M. (2019). Physics teaching and learning with multimedia applications: A review of teacher-oriented literature in 34 local language journals from 2006 to 2015. International Journal of Science Education, 41(9), 1181-1206.

https://doi.org/10.1080/09500693.2019.1597313

Gunawan, G., Harjono, A., Herayanti, L., \& Husein, S. (2019). Problem-based learning approach with supported interactive multimedia in physics course: Its effects on critical thinking disposition. Journal for the Education of Gifted Young Scientists, 1075-1089. https://doi.org/10.17478/jegys.627162

Henriksen, E. K., Bungum, B., Angell, C., Tellefsen, C. W., Frågåt, T., \& Bøe, M. V. (2014). Relativity, Quantum Physics and philosophy in the upper secondary curriculum: Challenges, opportunities and proposed approaches. Physics Education, 49(6), 678-684. https://doi.org/10.1088/0031-9120/49/6/678

Hopia, H., Latvala, E., \& Liimatainen, L. (2016). Reviewing the methodology of an Integrative Review. Scandinavian Journal of Caring Sciences, 30(4), 662-669. https://doi.org/10.1111/scs.12327

Jian-hua, S., \& hong, L. (2012). Explore the effective use of multimedia technology in college physics teaching. Energy Procedia, 17, 1897-1900.

https://doi.org/10.1016/j.egypro.2012.02.329

Kohnle, A., Bozhinova, I., Browne, D., Everitt, M., Fomins, A., Kok, P., Kulaitis, G., Prokopas, M., Raine, D., \& Swinbank, E. (2013). A new introductory quantum mechanics curriculum. European Journal of Physics, 35(1), 015001. https://doi.org/10.1088/0143o807/35/1/015001

Kohnle, A., Cassettari, D., Edwards, T. J., Ferguson, C., Gillies, A. D., Hooley, C. A., Korolkova, N., Llama, J., \& Sinclair, B. D. (2012). A new multimedia resource for teaching Quantum Mechanics Concepts. American Journal of Physics, 8o(2), 148-153. https://doi.org/10.1119/1.3657800

Krippendorff, K. (2018). Content analysis: An introduction to its methodology. Sage publications.

Lai, J. W. M., \& Bower, M. (2019). How is the use of technology in education evaluated? A systematic review. Computers \& Education, 133, 27-42.

https://doi.org/10.1016/j.compedu.2019.01.010

Mason, A., \& Singh, C. (2010). Do advanced physics students learn from their mistakes without explicit intervention? American Journal of Physics, 78(7), 760-767. https://doi.org/10.1119/1.3318805

Mayer, R. E. (2011). Applying the science of learning to multimedia instruction. Psychology of Learning and Motivation, 77-108. https://doi.org/10.1016/b978-0-12-387691-1.00003-X

Moral-Muñoz, J. A., Herrera-Viedma, E., Santisteban-Espejo, A., \& Cobo, M. J. (2020). Software tools for conducting Bibliometric Analysis in science: An up-to-date review. El Profesional De La Información, 29(1). https://doi.org/10.3145/epi.2020.ene.03 
Newman, M., \& Gough, D. (2019). Systematic reviews in educational research: Methodology, perspectives and application. Systematic Reviews in Educational Research, 3-22. https://doi.org/10.1007/978-3-658-27602-7_1

Pun, M. (2014). The use of multimedia technology in English language teaching: A global perspective. Crossing the Border: International Journal of Interdisciplinary Studies, 1(1), 29-38. https://doi.org/10.3126/ctbijis.v1i1.10466

Radlovic-Cubrilo, D., Lozanov-Crvenkovic, Z., Obadovic, D., \& Segedinac, M. (2014). The application of multimedia and its effects on teaching physics in Secondary School. Zbornik Instituta Za Pedagoska Istrazivanja, 46(2), 339-363. https://doi.org/10.2298/zipi1402339r

Rusanganwa, J. (2013). Multimedia as a means to enhance teaching technical vocabulary to physics undergraduates in Rwanda. English for Specific Purposes, 32(1), 36-44. https://doi.org/10.1016/j.esp.2012.07.002

Vaismoradi, M., Jones, J., Turunen, H., \& Snelgrove, S. (2016). Theme development in qualitative content analysis and thematic analysis. Journal of Nursing Education and Practice, 6(5).

Wuttiprom, S., Sharma, M. D., Johnston, I. D., Chitaree, R., \& Soankwan, C. (2009). Development and use of a conceptual survey in introductory quantum physics. International Journal of Science Education, 31(5), 631-654. https://doi.org/10.1080/09500690701747226

Zainuddin, Hasanah, A. R., Salam, M. A., Misbah, \& Mahtari, S. (2019). Developing interactive multimedia in physics learning. Journal of Physics: Conference Series, 1171, 012019. https://doi.org/10.1088/1742-6596/1171/1/012019 